\title{
Evaluation of ACPs in China Fusion Engineering Test Reactor Using CATE 2.1 Code
}

\author{
Lu Li, ${ }^{1}$ Jingyu Zhang, ${ }^{1}$ Qingyang Guo, ${ }^{1}$ Xiaokang Zhang, ${ }^{2}$ Songlin Liu, ${ }^{2}$ and Yixue Chen ${ }^{1}$ \\ ${ }^{1}$ School of Nuclear Science and Engineering, North China Electric Power University, Beijing 102206, China \\ ${ }^{2}$ Institute of Plasma Physics, Chinese Academy of Sciences, Hefei, Anhui 230031, China \\ Correspondence should be addressed to Yixue Chen; yxchen1972@126.com
}

Received 23 September 2016; Accepted 29 November 2016; Published 9 January 2017

Academic Editor: Arkady Serikov

Copyright (c) $2017 \mathrm{Lu} \mathrm{Li}$ et al. This is an open access article distributed under the Creative Commons Attribution License, which permits unrestricted use, distribution, and reproduction in any medium, provided the original work is properly cited.

\begin{abstract}
Activated corrosion products (ACPs) are the dominant radiation hazard in water-cooled fusion reactor under normal operation conditions and directly determine the occupational radiation exposure during operation and maintenance. Recently, the preliminary design of China Fusion Engineering Test Reactor (CFETR) has been just completed. Evaluation of ACPs is an important work for the safety of CFETR. In this paper, the ACPs analysis code CATE 2.1 was used to simulate the spatial distribution of ACPs along the blanket cooling loop of CFETR, in which the influence of adopting different pulse handling methods was researched. At last, the dose rate caused by ACPs around the blanket cooling loop was calculated using the point kernel code ARShield. The results showed that the dose rate under normal operation for 1.2 years at contact is $1.02 \mathrm{mSv} / \mathrm{h}$ and at $1 \mathrm{~m}$ away from pipe is $0.45 \mathrm{mSv} / \mathrm{h}$. And after shutting down the reactor, there will be a rapid decrease of dose rate, because of the rapid decay of short-lived ACPs.
\end{abstract}

\section{Introduction}

According to the surveillance data of French PWR plants, more than $90 \%$ of occupational radiation exposure (ORE) of personnel under normal operation is due to the activated corrosion products (ACPs) in the primary coolant circuit [1]. And, for the water-cooled fusion reactor ITER, the gamma ray from ACPs is also a major contributor to ORE [2].

In the cooling loop of water-cooled reactor, the corrosion is caused by the contact of water and metal material. For instance, the pipe materials of blanket and heat exchanger are corroded by the coolant and plenty of metallic oxides are produced. Ion based alloy and nickel based alloy are the main materials used in fusion reactor, and the corrosion by water is inevitable and producing the main corrosion products $(\mathrm{CPs})$ $\mathrm{Fe} / \mathrm{Ni} / \mathrm{Cr} / \mathrm{Co} / \mathrm{Mn}$ and so forth.

Some CPs are released into coolant and then transported to the region under neutron flux by coolant, such as first wall, blanket, divertor, and vacuum chamber. The CPs in the coolant and on the pipe here absorb neutron and become radioactive, which are called activated corrosion products
(ACPs). Some ACPs are transported and deposited on other places carried by the coolant, such as heat exchanger, pipe, valve, pump, and filter.

The research on ACPs of fusion reactor originates from pressurized water reactor (PWR), because both have similar thermal-hydraulic design. The related research on PWR started more than 50 years ago and dozens of models and codes have been developed, so worldwide comparison and verification can be done and it is very helpful. But for ACPs in water-cooled fusion reactor, it is still at an early stage of research. In the 20th century, only two codes, PACTITER [3] from CEA and TRACT [4] from UKAEA, were developed, and the authorized scope of use is limited. For the ACPs analysis of ITER and CFETR (China Fusion Engineering Test Reactor), the code CATE [5, 6] (Corrosion, Activation, and Transport Evaluation) was developed by the author since 2013. In the version of CATE 2.0, a three-region transport model was adopted based on the theory of driving force from the concentration difference, which makes CATE able to simulate the spatial distribution of ACPs. Moreover, considering the characteristic of pulse operation of fusion 


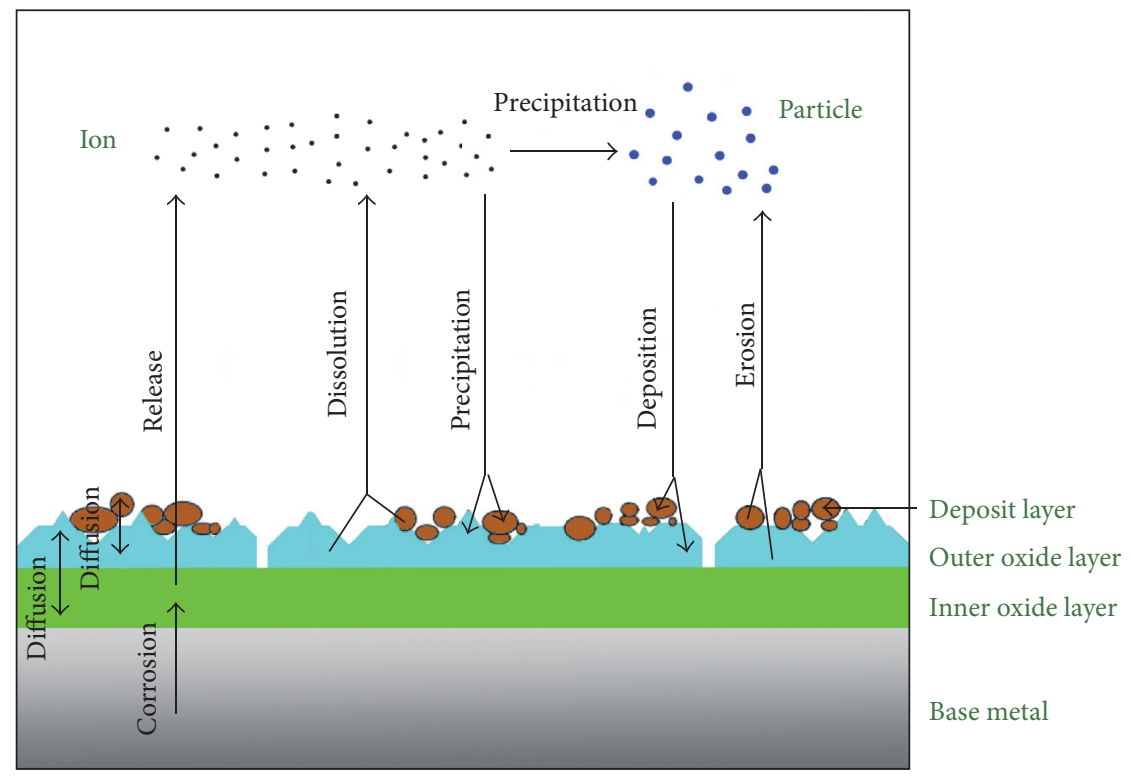

FIGURE 1: The production mechanism of corrosion products.

reactor, the related handling method was researched in this paper and incorporated in CATE, making CATE updated to version 2.1 .

The basic theory and equations of the three-node transport model were described in Section 2 of this paper, and the ACPs radioactivity of blanket cooling loop in CFETR was simulated using CATE 2.1 in Section 3. In Section 4, a comprehensive comment was presented.

\section{Model and Database in CATE 2.1}

2.1. Description of the Three-Node Transport Model. Figure 1 presents the mechanism of generating corrosion products (CPs). Under high pressure and high temperature, the base metal is easily corroded by the coolant, and then the oxide layers are generated. Some ions pass through the oxide layers and enter into the coolant. When the coolant is supersaturated, the ions will precipitate on the outer oxide layer or into particles in the coolant, while when the coolant is unsaturated, the deposit on the outer oxide layer will redissolve into the coolant. In addition, under the shear force by the coolant, the deposit on the outer oxide layer will be eroded into particles and then enter into the coolant.

In the code CATE, some hypotheses are adopted as follows:

(1) The loop is divided into two parts according to the neutron flux and temperature. The places with high temperature and under high neutron flux, such as first wall, blanket, and diverter, are named "In-Flux" region, while the other places without neutron flux and with relative low temperature, such as pipe, pump, valve, and heat exchanger, are named "OutFlux" region.
(2) Considering that the velocity of coolant is as fast as several $\mathrm{m} / \mathrm{s}$, the coolant will be well mixed rapidly, so it can be assumed that the coolant is homogeneous along the cooling loop. There is no need to divide the coolant into In-Flux coolant or Out-Flux coolant, and the coolant can be treated as a node.

(3) In order to simplify the model, the ACPs are divided into two forms, solid form and liquid form. And the three nodes are In-Flux surface, Out-Flux surface, and coolant, which is called "three-node transport model."

(4) In the calculation of CPs solubility in the coolant near the pipe surface, the temperature of the wall is used [7].

(5) The CPs formed by activation or decay of ACPs are neglected, because the quantity of ACPs is much smaller than that of CPs.

Figure 2 presents the transport process of ACPs based on three-node model.

The mass balance equations for CPs are as follows, in which $I_{C}, I_{1}$, and $I_{3}$, respectively, indicate the mass of CPs in coolant, on the In-Flux surface and on the Out-Flux surface.

In-Flux:

$$
\frac{d I_{1}}{d t}=\frac{\operatorname{Cor}_{1} \cdot S_{1}}{\alpha}+K_{1}\left(S\left(T_{1}+\Delta T_{1}\right)-S\left(T_{1}\right)\right) .
$$

Out-Flux:

$$
\frac{d I_{3}}{d t}=\frac{\operatorname{Cor}_{3} \cdot S_{3}}{\alpha}+K_{3}\left(S\left(T_{3}+\Delta T_{3}\right)-S\left(T_{3}\right)\right) .
$$




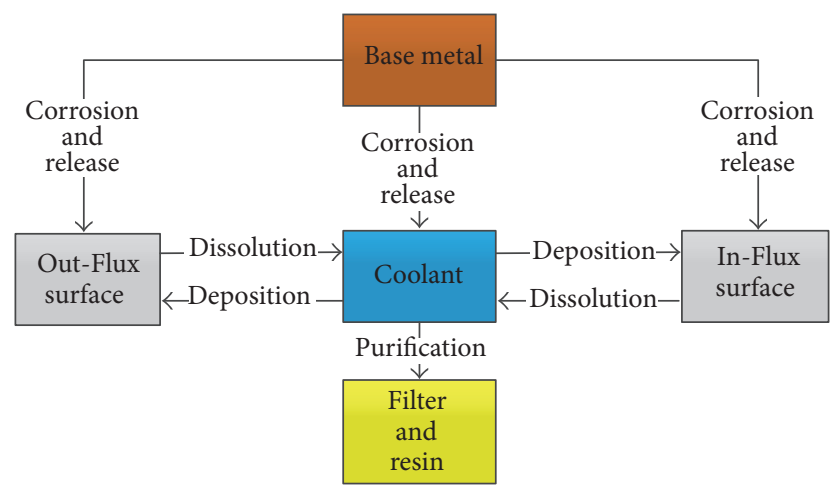

FIGURE 2: The transport process of ACPs based on three-node model.

Coolant:

$$
\begin{aligned}
\frac{d I_{C}}{d t}= & \operatorname{Cor}_{1} \cdot S_{1}+\operatorname{Cor}_{3} \cdot S_{3} \\
& -K_{1}\left(S\left(T_{1}+\Delta T_{1}\right)-S\left(T_{1}\right)\right) \\
& -K_{3}\left(S\left(T_{3}+\Delta T_{3}\right)-S\left(T_{3}\right)\right)-\frac{Q \omega}{V_{F}} I_{C} \\
& -\sigma \phi I_{C} R .
\end{aligned}
$$

The nuclide number balance equations for activated corrosion products are as follows, in which $N_{C}, N_{1}$, and $N_{3}$ indicate, respectively, the nuclide number of ACPs in coolant, on the In-Flux surface, and on the Out-Flux surface.

In-Flux:

$$
\begin{aligned}
\frac{d N_{1}}{d t}= & \sum \lambda \chi N_{n-1}+\sum \sigma \phi \frac{I_{1} N_{A}}{A} \\
& +K_{1}^{a}\left(\frac{N_{C}}{I_{C}} S\left(T_{1}+\Delta T_{1}\right)-\frac{N_{1}}{I_{1}} S\left(T_{1}\right)\right)-\lambda N_{1} \\
& -\sigma^{\prime} \phi N_{1} .
\end{aligned}
$$

Out-Flux:

$$
\begin{aligned}
\frac{d N_{3}}{d t}= & \sum \lambda \chi N_{n-1} \\
& +K_{3}^{a}\left(\frac{N_{C}}{I_{C}} S\left(T_{3}+\Delta T_{3}\right)-\frac{N_{3}}{I_{3}} S\left(T_{3}\right)\right)-\lambda N_{3} .
\end{aligned}
$$

Coolant:

$$
\begin{aligned}
\frac{d N_{C}}{d t}= & \sum \lambda \chi N_{n-1}+\sum \sigma \phi \frac{I_{1} N_{A}}{A}-\lambda N_{C}-\sigma^{\prime} \phi N_{C} \cdot R \\
& -\frac{Q \omega}{V_{F}} \frac{N_{C}}{I_{C}} S\left(T_{C}\right) \\
& -\sum K_{1}^{a}\left(\frac{N_{C}}{I_{C}} S\left(T_{1}+\Delta T_{1}\right)-\frac{N_{1}}{I_{1}} S\left(T_{1}\right)\right) \\
& -\sum K_{3}^{a}\left(\frac{N_{C}}{I_{C}} S\left(T_{3}+\Delta T_{3}\right)-\frac{N_{3}}{I_{3}} S\left(T_{3}\right)\right),
\end{aligned}
$$

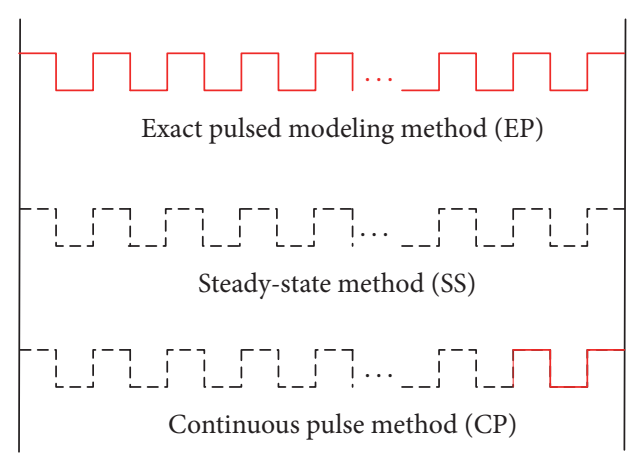

FIGURE 3: Different handling methods of pulse.

where Cor is the corrosion rate, $\mathrm{g} /\left(\mathrm{m}^{2} \cdot \mathrm{s}\right)$; $S$ is the surface area, $\mathrm{m}^{2} ; \alpha$ is ratio of release rate to corrosion rate of the corrosion products, $\% ; K_{i}$ is mass transfer coefficient of nuclide $m,(\mathrm{~mol} / \mathrm{s}) /\left(\mathrm{m}^{2} \cdot \mathrm{mol} / \mathrm{m}^{3}\right)=\mathrm{m} / \mathrm{s} ; A$ is contact area between coolant and pipe, $\mathrm{m}^{2} ; S(T)$ is solubility of nuclide $m$ in the coolant under $T{ }^{\circ} \mathrm{C}, \mathrm{kg} / \mathrm{m}^{3} ; \sigma$ is radioactive capture cross section of converting nuclide $m$ to nuclide $n$, barn; $\phi$ is neutron flux, $\mathrm{n} /\left(\mathrm{cm}^{2} \cdot \mathrm{s}\right)$; $\mathrm{Q}$ is volume flow rate of coolant into CVCS, $\mathrm{m}^{3} / \mathrm{s} ; \omega$ is collection efficiency of filter and resin in chemical and volume control system (CVCS), \%; $V_{F}$ is coolant volume in CVCS, $\mathrm{m}^{3} ; R$ is ratio of coolant residence time in the region of In-Flux pipe to that in the whole cooling loop, $\% ; \lambda$ is decay constant of nuclide, $\mathrm{s}^{-1} ; \chi$ is decay branching ratio from parent nuclide to daughter nuclide, $\%$.

The three-node model was applied in CATE for the simulation of ACPs in LIM-OBB loop of ITER, and the results were compared with that from similar codes TRACT and PACTITER. The three codes are in good agreement with each other [8].

2.2. Description of Method for Pulse Handling. Because of the limitation of electric field and magnetic field, the plasma of fusion reactor cannot be sustained and has to be operated by pulse mode, so the neutron produced by the plasma is also pulsing. The pulse time is in several minutes to one hour. The operation lifetime of fusion reactor is about 30 years or longer. In the calculation, because the step time must be no bigger than the pulse time, the total simulation of the operation lifetime of fusion reactor is very time-consuming.

Several handling methods have been proposed previously, such as exact pulse modeling (EP) method, equivalent steady-state (ESS) method, steady-state (SS) method, and continuous pulse (CP) method.

Exact pulse modeling (EP) method [9] does not introduce any level of approximation, but it consumes considerable long time. The steady-state (SS) method [10] keeps operation time unchanged, but the neutron flux is scaled by the ratio of the irradiation time to the operation time. The continuous pulse (CP) method [11] is assumed to be consisting of a continuous irradiation period followed by only a few pulses prior to shutdown. The different methods dealing with pulse are shown in Figure 3. 


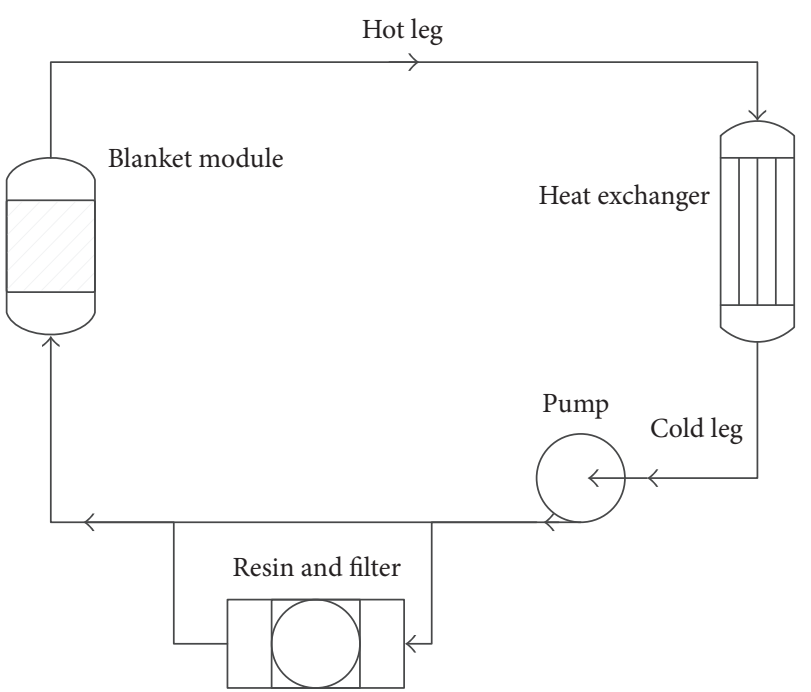

FIGURE 4: Schematic of CFETR blanket loop.

TABLE 1: The preliminary design data of CFETR blanket loop.

\begin{tabular}{lc}
\hline Parameter & Value \\
\hline In-Flux flow rate $(\mathrm{m} / \mathrm{s})$ & $2 \sim 6$ \\
Out-Flux flow rate $(\mathrm{m} / \mathrm{s})$ & $6 \sim 9$ \\
Coolant inventory $\left(\mathrm{m}^{3}\right)$ & 40.9 \\
Pulse length $(\mathrm{s})$ & 1000 \\
Pressure $(\mathrm{MPa})$ & $14.9 \sim 15.5$ \\
Coolant temperature $\left({ }^{\circ} \mathrm{C}\right)$ & $285 \sim 325$ \\
Coolant density $\left(\mathrm{kg} / \mathrm{m}^{3}\right)$ & $660 \sim 755$ \\
Neutron flux $\left(\mathrm{n} /\left(\mathrm{m}^{2} \cdot \mathrm{s}\right)\right)$ & $5.18 E+17$ \\
Filter flow rate $(\mathrm{kg} / \mathrm{s})$ & $1.72 E-2$ \\
Filter factor & $50 \%$ \\
\hline
\end{tabular}

The EP, SS, and CP methods of pulse handling are all incorporated in CATE 2.1, and the users can select any one for their convenience.

2.3. The Nuclear Database. The nuclear data, including halflife, decay branching ratio, cross section data are derived from the European Activation File EAF-2007 [12, 13], in which the cross section is stored in several energy group structures and for different reactor types. In the following calculation, the cross section of 175-group VITAMIN-J structure for fusion device was used.

When the neutron spectrum is given by the user, the CATE code is able to collapse the cross section with the corresponding energy group structure into one group following the rule of conservation of reaction rate.

\section{Evaluation of ACPs in CFETR}

3.1. Description of the Blanket Loop in CFETR. The schematic of CFETR blanket loop and the preliminary design data of CFETR blanket loop are, respectively, presented in Figure 4 and Table 1.
TABLE 2: The element composition of SS316-LN.

\begin{tabular}{lc}
\hline Element & content \\
\hline $\mathrm{C}$ & 0.03 \\
$\mathrm{Mn}$ & 2 \\
$\mathrm{Si}$ & 1 \\
$\mathrm{Cr}$ & 17.5 \\
$\mathrm{Ni}$ & 11.5 \\
$\mathrm{P}$ & 0.04 \\
$\mathrm{~S}$ & 0.015 \\
$\mathrm{Mo}$ & 2.25 \\
$\mathrm{~N}$ & 0.11 \\
$\mathrm{Co}$ & 0.05 \\
$\mathrm{Nb}$ & 0.1 \\
$\mathrm{~B}$ & 0.001 \\
$\mathrm{Fe}$ & 65.404 \\
\hline
\end{tabular}

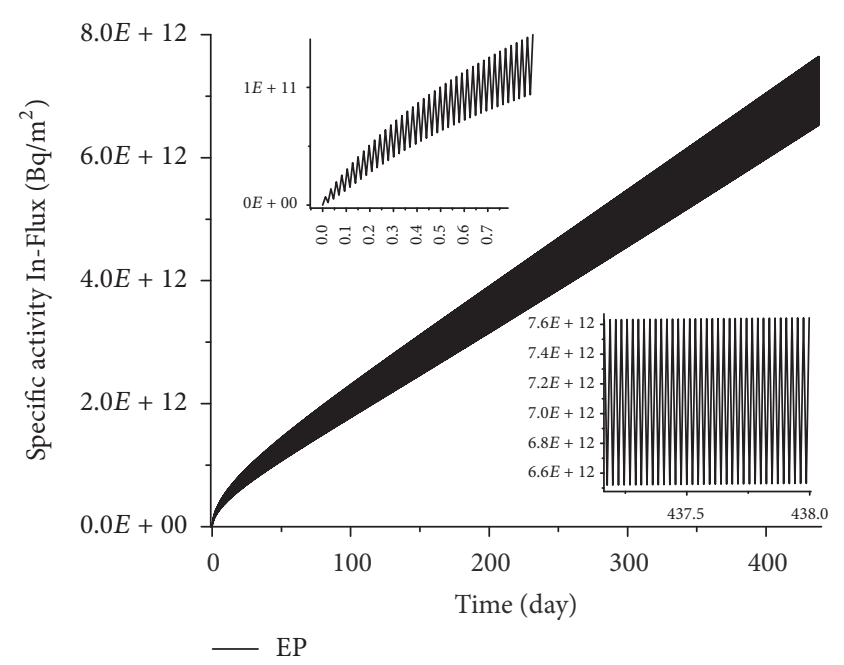

Figure 5: The specific activity of In-Flux region with EP method.

The material used in the loop is SS316-LN and the element composition is presented in Table 2. The corrosion rate of SS316-LN at $300^{\circ} \mathrm{C}$ and $15.5 \mathrm{MPa}$ derived from experiment is as follows:

$$
\mathrm{CR}=7.806 \times 10^{-5} \times t^{-0.5} \mathrm{~kg} \cdot \mathrm{m}^{-2} \cdot \mathrm{h}^{-1} .
$$

3.2. Calculation of ACPs Activity Using CATE 2.1. CATE 2.1 has the ability to deal with pulse in three methods, which are EP, SS, and CP. Taking the calculation results of In-Flux region as example, the specific activity varying with time is shown in Figures 5, 6, and 7, respectively, with EP, SS, and CP methods. And the comparison of different methods is shown in Figure 8.

From Figure 8, it can be seen that the results of the three methods have the same tendency, and the results of SS and $\mathrm{CP}$ are between the upper and lower boundary of EP, so the results are acceptable. But SS method is not suitable for the short-lived nuclides, because the short-lived nuclides decay sharply without neutron pulse, and the SS method cannot reflect this effect. The results of $\mathrm{CP}$ are similar to those of 


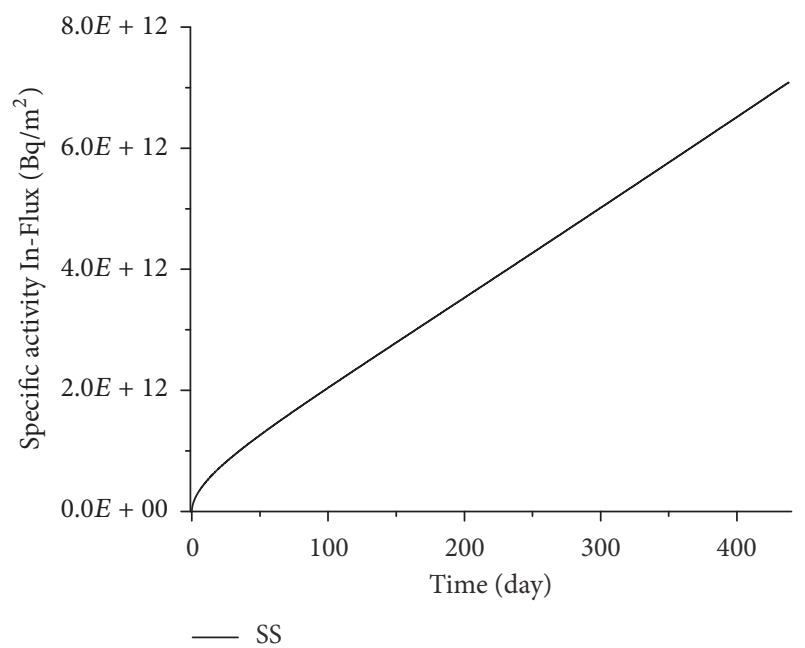

FIGURE 6: The specific activity of In-Flux region with SS method.

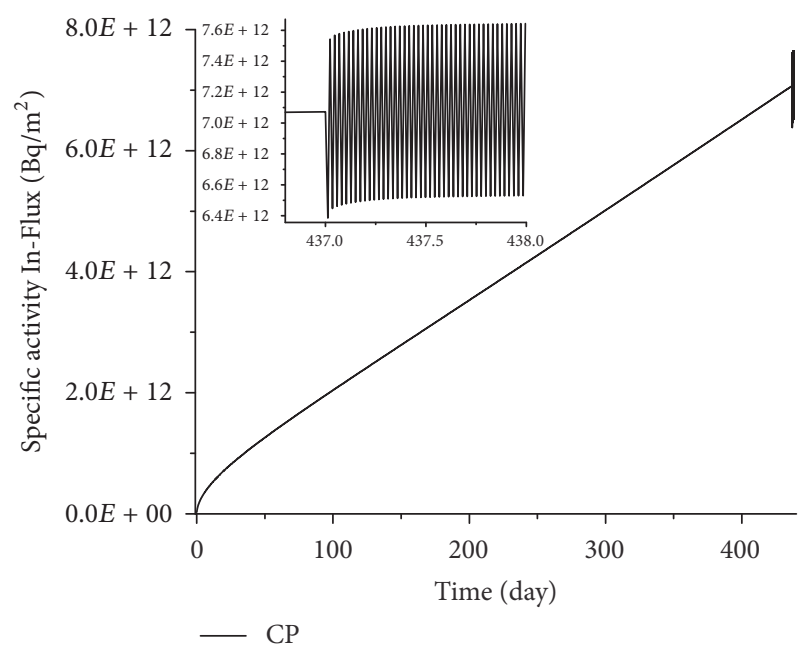

FIGURE 7: The specific activity of In-Flux region with CP method.

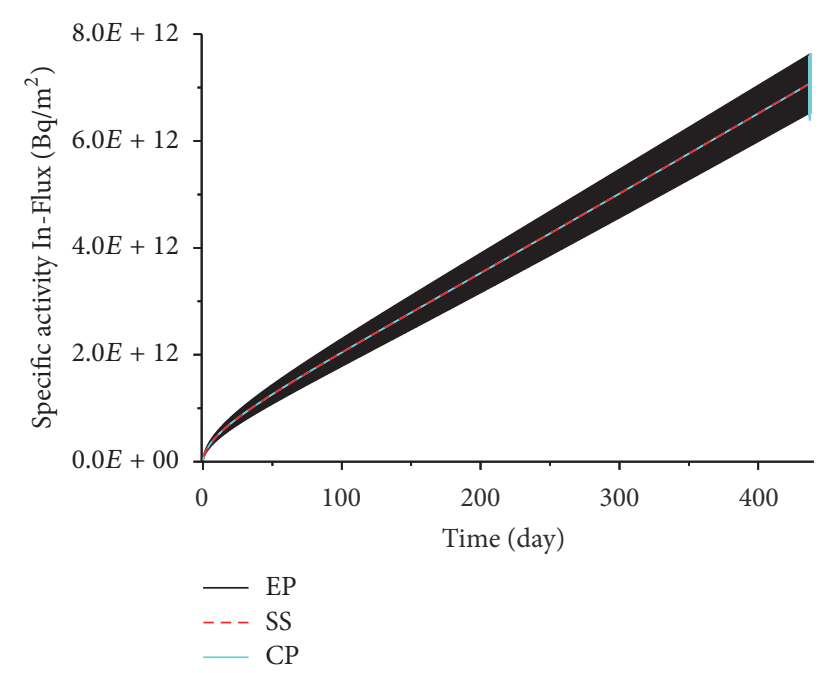

FIgURE 8: The comparison of different handling methods of pulse.

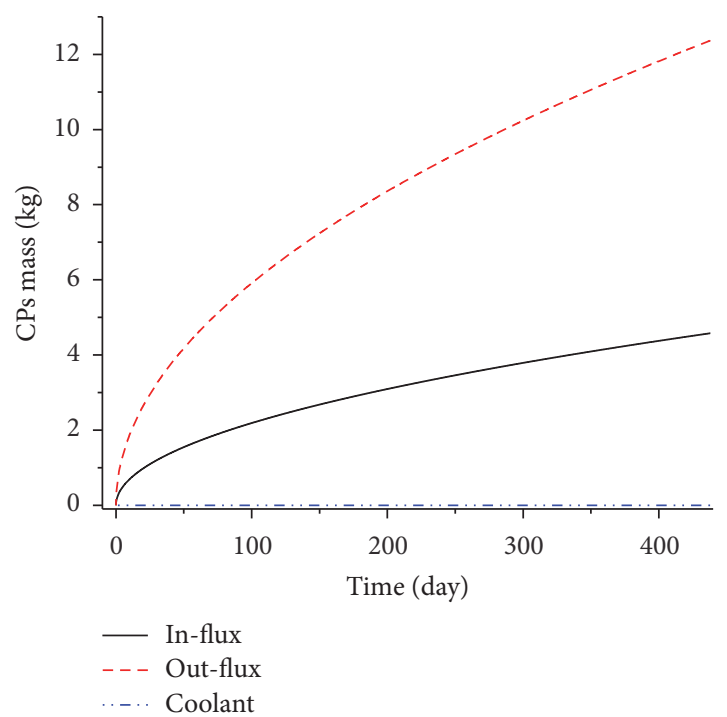

FIgURE 9: Variation tendency of CPs mass over time from CATE.

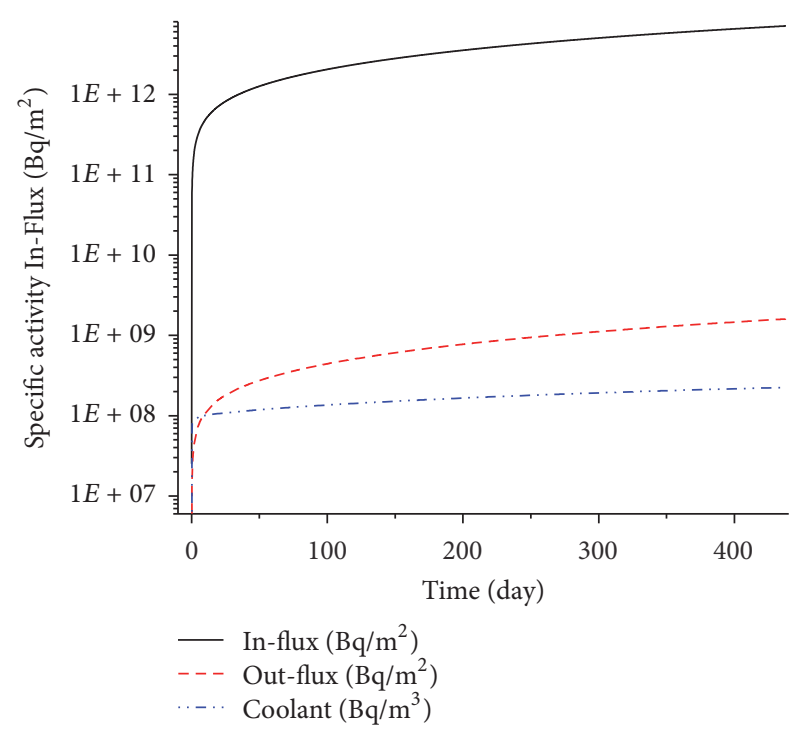

FIGURE 10: Variation tendency of ACPs activity over time from CATE.

SS in the early stage, and during the last several pulses they are close to those of EP. As stated in Section 2.2, although the EP method has high accuracy, it is very time-consuming. For overall consideration of the computation accuracy and efficiency, the CP method is highly recommended and set as the default method in CATE.

In Table 3, the calculation results of CPs and ACPs with $\mathrm{CP}$ method for 1.2 years of operation are presented.

The variation tendency of CPs mass and ACPs specific activity over time are given in Figures 9 and 10. In order to visually compare the difference among the three regions, the SS method for pulse handling is employed here.

The solubility of $\mathrm{Fe}$, the main corrosion product element, decreases as the temperature increases. Under normal operation of steady-state, the temperature of Out-Flux region is 
TABLE 3: The calculation results of CPs and ACPs.

\begin{tabular}{lccccc}
\hline \multicolumn{2}{c}{ Pipe surface } & \multicolumn{3}{c}{ ACPs } \\
In-flux $(\mathrm{kg})$ & Out-flux $(\mathrm{kg})$ & Coolant $(\mathrm{kg})$ & In-flux $\left(\mathrm{Bq} / \mathrm{m}^{2}\right)$ & Out-flux $\left(\mathrm{Bq} / \mathrm{m}^{2}\right)$ & Coolant $\left(\mathrm{Bq} / \mathrm{m}^{3}\right)$ \\
\hline $4.58 E+00$ & $1.24 E+01$ & $5.35 E-05$ & $7.64 E+12$ & $1.61 E+09$ & $2.43 E+08$ \\
\hline
\end{tabular}

TABLE 4: The nuclide composition and special activity of ACPs at shutdown.

\begin{tabular}{lcccc}
\hline Nuclide & Decay constant $\left(\mathrm{s}^{-1}\right)$ & $\begin{array}{c}\text { Specific activity on In-Flux } \\
\text { surface }\left(\mathrm{Bq} / \mathrm{m}^{2}\right)\end{array}$ & $\begin{array}{c}\text { Specific activity on } \\
\text { Out-Flux surface }\left(\mathrm{Bq} / \mathrm{m}^{2}\right)\end{array}$ & $\begin{array}{c}\text { Specific activity in coolant } \\
\left(\mathrm{Bq} / \mathrm{m}^{3}\right)\end{array}$ \\
\hline FE-55 & $8.03 E-09$ & $2.92 E+12$ & $7.81 E+08$ & $9.27 E+07$ \\
MN-56 & $7.46 E-05$ & $2.14 E+12$ & $4.15 E+08$ & $6.80 E+07$ \\
MN-54 & $2.57 E-08$ & $5.24 E+11$ & $1.40 E+08$ & $1.66 E+07$ \\
AL-28 & $5.16 E-03$ & $3.80 E+11$ & $4.16 E+06$ & $1.21 E+07$ \\
FE-53 & $1.36 E-03$ & $2.76 E+11$ & $1.01 E+07$ & $8.75 E+06$ \\
CO-57 & $2.95 E-08$ & $2.46 E+11$ & $6.58 E+07$ & $7.81 E+06$ \\
MO-99 & $2.92 E-06$ & $2.23 E+11$ & $5.87 E+07$ & $7.07 E+06$ \\
TC-99M & $3.20 E-05$ & $1.96 E+11$ & $5.23 E+07$ & $6.21 E+06$ \\
CO-58 & $1.13 E-07$ & $1.55 E+11$ & $4.13 E+07$ & $4.91 E+06$ \\
CO-60M & $1.10 E-03$ & $1.28 E+11$ & $4.90 E+06$ & $4.05 E+06$ \\
FE-53M & $4.48 E-03$ & $1.19 E+11$ & $1.48 E+06$ & $3.77 E+06$ \\
CO-58M & $2.16 E-05$ & $1.14 E+11$ & $2.74 E+07$ & $3.61 E+06$ \\
MO-91 & $7.46 E-04$ & $8.24 E+10$ & $4.34 E+06$ & $2.61 E+06$ \\
CR-51 & $2.90 E-07$ & $8.17 E+10$ & $2.18 E+07$ & $2.59 E+06$ \\
NI-57 & $5.36 E-06$ & $5.66 E+10$ & $1.47 E+07$ & $1.80 E+06$ \\
\hline
\end{tabular}

lower than that of In-Flux region. As a result, the solubility of $\mathrm{Fe}$ in the In-Flux region is lower than that in the OutFlux region. According to the theory of driving force from the concentration difference, the CPs migrate from Out-Flux region to In-Flux region carried by coolant.

The ACPs are mainly produced in the In-Flux region and released into the coolant directly, and then part of ACPs carried by the coolant deposit on the Out-Flux surface. As a result, the specific activity in the Out-Flux region is smaller than that in the In-Flux region.

Table 4 presents the main radionuclides produced in the circuit with CP method for 1.2 years of operation.

The data in Table 4 indicates that the main contributors to the radioactivity in all the three regions are $\mathrm{Fe}-55 / \mathrm{Mn}$ $56 / \mathrm{Mn}-54 / \mathrm{Al}-28 / \mathrm{Fe}-53$, which account for more than $80 \%$ radioactivity. The short-lived nuclides account for $42.9 \%$ and $27.8 \%$, respectively, in the In-Flux region and Out-Flux region. If nothing is done but keeping the device cooling down when the fusion device shuts down under maintenance state, the activity will distinctly decrease because of the fast decay of short-lived nuclides.

3.3. Calculation of Dose Rate Caused by ACPs Using ARShield Code. The ARShield code is an advanced version of point kernel code, developed by North China Electric Power University. It provides the prejob for visualization of largescale radiation field and virtual roaming in nuclear plant, by breaking the restrictions of the traditional point kernel integration codes. The detailed characteristics of ARShield can be seen from [14].

The density of each radionuclide at chosen region calculated by CATE 2.1 is introduced into ARShield and then converted to dose rate using point kernel integration method, which is as follows:

$$
\begin{aligned}
& D(r) \\
& =\int \frac{K s\left(r^{\prime}\right) B\left(\mu\left|r \longrightarrow r^{\prime}\right|, E\right) \exp \left(-\mu\left|r \longrightarrow r^{\prime}\right|\right) d V}{4 \pi\left|r \longrightarrow r^{\prime}\right|^{2}},
\end{aligned}
$$

where $r$ is point at which gamma dose rate is to be calculated, $r^{\prime}$ is location of source in volume $V, V$ is volume of source region, $\mu$ is total attenuation coefficient at energy $E,\left|r \rightarrow r^{\prime}\right|$ is distance between source point and point at which gamma intensity is to be calculated, $K$ is flux-to-dose conversion factor, and $B$ is dose buildup factor.

The geometry of hot leg pipe, linking the blanket and the heat exchanger, is adopted for dose rate calculation here, which has an internal diameter of $0.527 \mathrm{~m}$, thickness of $0.02 \mathrm{~m}$, and length of $33 \mathrm{~m}$. The dose rate around the hot leg pipe under normal operation at 1.2 years calculated by ARShield is shown in Table 5.

From Table 5, it can be seen that the dose rate at contact is $1.02 \mathrm{mSv} / \mathrm{h}$ and at $1 \mathrm{~m}$ away from pipe is $0.45 \mathrm{mSv} / \mathrm{h}$. After shutting down the reactor, there is a rapid decrease of the 
TABLE 5: The dose rate caused by ACPs around the hot leg pipe.

\begin{tabular}{lc}
\hline Contact dose rate $(\mu \mathrm{Sv} / \mathrm{h})$ & Dose rate at $1 \mathrm{~m}$ away $(\mu \mathrm{Sv} / \mathrm{h})$ \\
\hline $1.02 E+03$ & $4.50 E+02$ \\
\hline
\end{tabular}

dose rate, because of the rapid decay of short-lived nuclides, such as Mn-56. But the long-lived nuclides, such as $\mathrm{Mn}$ $54 / \mathrm{Co}-57 / \mathrm{Co}-58 / \mathrm{Cr}-51$, decay very slowly and become the main source of dose rate.

\section{Conclusions}

In this paper, the different methods for pulse handling were researched and incorporated in the ACPs analysis code CATE, making CATE updated to version 2.1. Then the preliminary design of blanket cooling loop of China Fusion Engineering Test Reactor (CFETR) was simulated using CATE, and CPs mass and ACPs activity were calculated. And the results of different methods for pulse handling are compared. At last, the dose rate around the cooling loop caused by ACPs was calculated by the point kernel code ARShield. The dose rate under normal operation for 1.2 years at contact is $1.02 \mathrm{mSv} / \mathrm{h}$ and at $1 \mathrm{~m}$ away from pipe is $0.45 \mathrm{mSv} / \mathrm{h}$. But after shutdown the dose rate will decrease obviously, which is caused by the fast decay of the short-lived ACPs. The rest of long-lived ACPs, such as $\mathrm{Mn}-54 / \mathrm{Co}-57 / \mathrm{Co}-$ $58 / \mathrm{Cr}-51$, become the main source of dose rate.

In the subsequent work, more attention will be paid to improve the analytical capability of CATE. A four-phase multinode model is under developing, in which each device in the cooling loop is regarded as an independent node. In this way, the fine distribution of ACPs along the cooling loop can be derived. And in the future, more operation condition will be simulated, such as startup and shutdown, when the coolant temperature is lower than $285^{\circ} \mathrm{C}$ and the coolant velocity is lower than $2 \mathrm{~m} / \mathrm{s}$.

\section{Competing Interests}

The authors declare that they have no competing interests.

\section{Acknowledgments}

The authors would like to express their gratitude for the support of the following: National Natural Science Foundation of China (Project 11605058), National Special Project for Magnetic Confined Nuclear Fusion Energy of China (Project 2014GB119000), and the National Magnetic Confinement Fusion Science Program of China (Project 2013GB108004).

\section{References}

[1] A. Rocher, J. L. Bretelle, and M. Berger, "Impact of main radiological pollutants on contamination risks (ALARA) optimization of physico chemical environment and retention technics during operation and shutdown," in Proceedings of the 4th European Workshop on Occupational Exposure Management at NPPs (ISOE04 '03), Orlando, Fla, USA, January 2003.
[2] C. B. A. Forty and P. J. Karditsas, "Preliminary cooling circuit activation and ORE assessment for ITER," in Proceedings of the 19th Symposium on Fusion Technology (SOFT '96), Lisbon, Portugal, September 1996.

[3] L. Di Pace, D. Tarabelli, and D. You, "Development of the PACTITER code and its application to the assessment of the ITER divertor cooling loop corrosion products," Fusion Technology, vol. 34, no. 3, pp. 733-737, 1998.

[4] P. J. Karditsas, "Activation product transport using TRACT: ORE estimation of an ITER cooling loop," Fusion Engineering and Design, vol. 45, no. 2, pp. 169-185, 1999.

[5] J. Zhang, L. Li, W. Song et al., "Program development for source term analysis of activated corrosion product in water-cooled fusion reactor," Atomic Energy Science and Technology, vol. 49S, pp. 68-74, 2015.

[6] L. Li, J. Zhang, W. Song, Y. Fu, X. Xu, and Y. Chen, "CATE: a code for activated corrosion products evaluation of watercooled fusion reactor," Fusion Engineering and Design, vol. 100, pp. 340-344, 2015.

[7] S. Nisan, L. D. Pace, and J.-C. Robin, "Evaluation of the activated corrosion products for the ITER heat transfer systems," in Fusion Technology, pp. 1763-1766, 1996.

[8] J. Zhang, L. Li, S. He, and Y. Chen, "Calculation of radioactivity and dose rate of activated corrosion products in water-cooled fusion reactor," Science and Technology of Nuclear Installations, vol. 2016, Article ID 6051834, 6 pages, 2016.

[9] P. P. H. Wilson and D. L. Henderson, "Qualitative analysis of physical and mathematical approximations necessary for induced radioactivity calculations in fusion devices," Fusion Engineering and Design, vol. 36, no. 2-3, pp. 415-427, 1997.

[10] J. F. Latkowski, J. Sanz, and J. L. Vujic, “The impact of pulsed irradiation upon neutron activation calculations for inertial and magnetic fusion energy power plants," Fusion Technology, vol. 30, no. 3, pp. 1470-1474, 1996.

[11] J. Sanz, O. Cabellos, P. Yuste, S. Reyes, and J. F. Latkowski, "Pulsed activation modeling for chamber materials of ife power reactors and experimental facilities," Fusion Technology, vol. 39, no. 2, pp. 996-1002, 2001.

[12] R. A. Forrest, J. Kopecky, and J.-Ch. Sublet, "The European Activation File: EAF-2007 neutron-induced cross section library," UKAEA FUS 535, 2007.

[13] R. A. Forrest, “The European Activation File: EAF-2007 decay data library," UKAEA FUS 537, 2007.

[14] S. He, Q. Zang, J. Zhang, H. Zhang, M. Wang, and Y. Chen, "Development and validation of an interactive efficient dose rates distribution calculation program arshield for visualization of radiation field in nuclear power plants," Radiation Protection Dosimetry, 2016. 

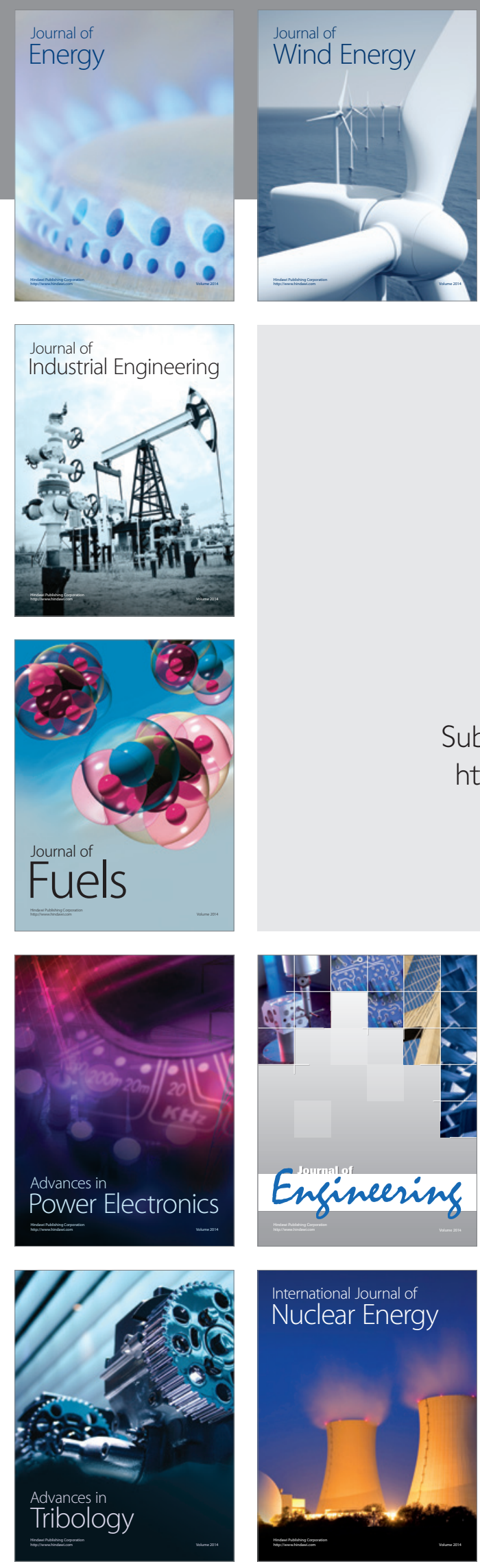

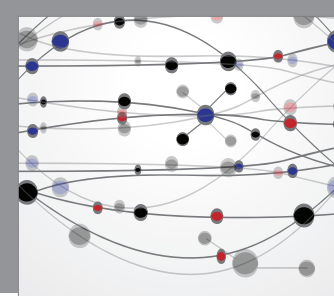

The Scientific World Journal
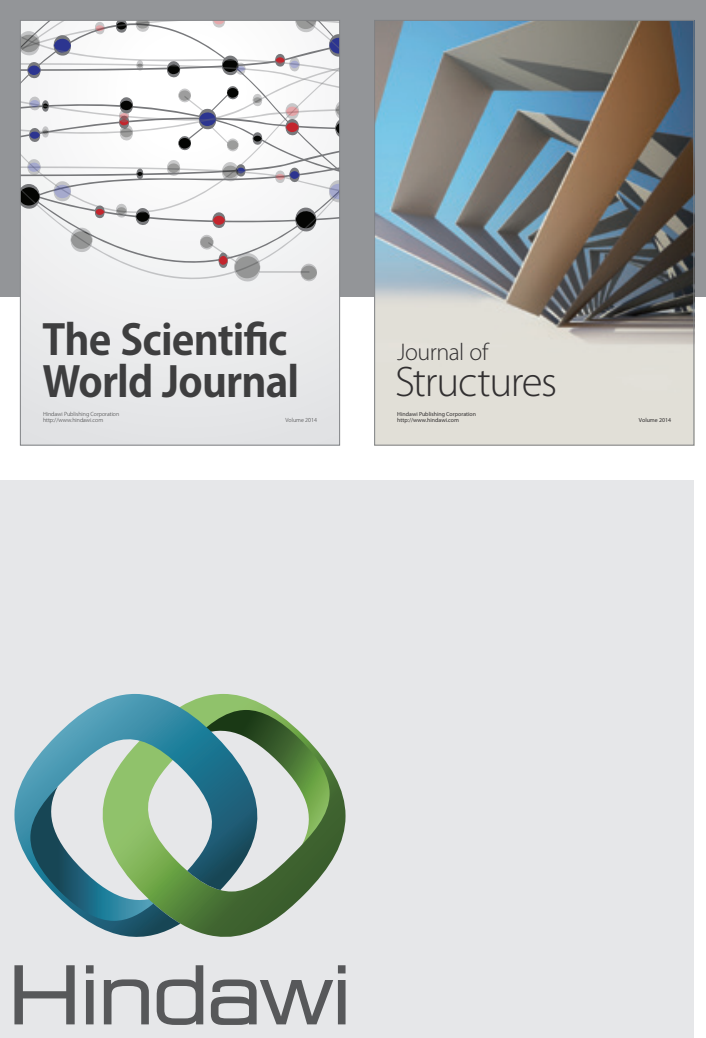

Submit your manuscripts at

https://www.hindawi.com
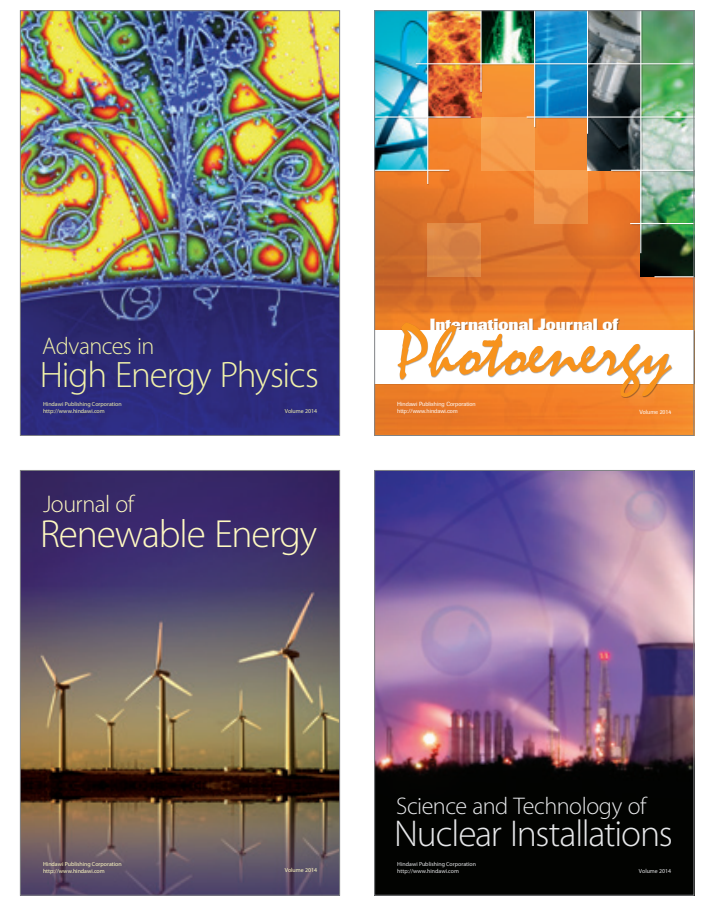
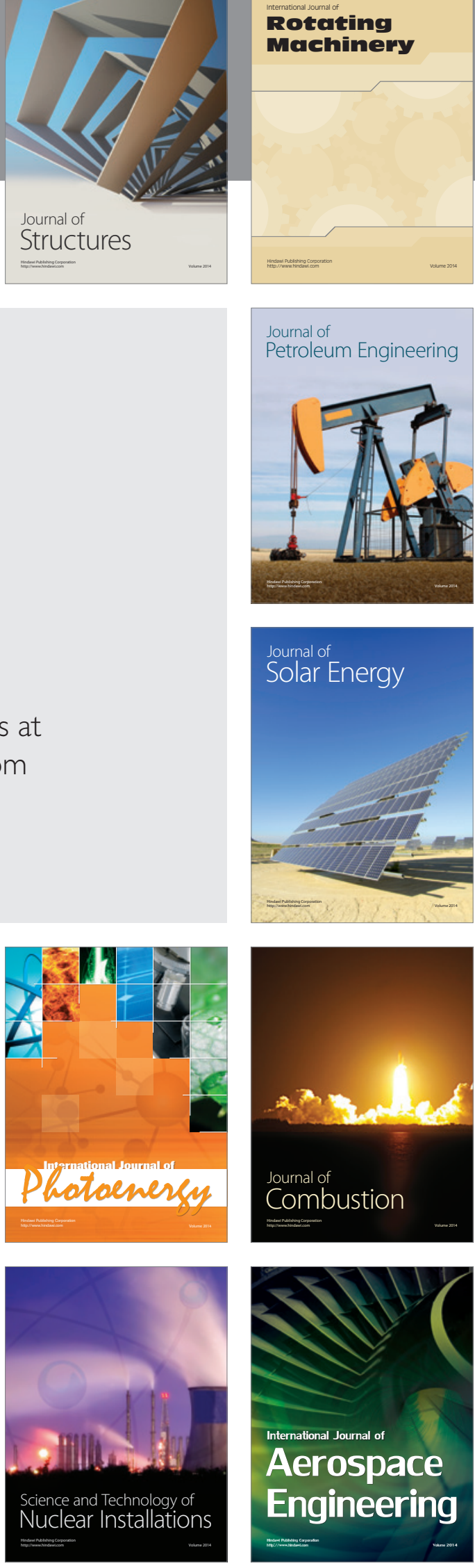